\title{
Clinical characteristics and outcomes of the oldest old people with type 2 diabetes - perspective from a tertiary diabetes center in Thailand
}

Thewjitcharoen Yotsapon ${ }^{*}$, Krittiyawong Sirinate, Wanothayaroj Ekgaluck, Vongterapak Somboon, Anuntakulnatee Tawee, Kittipoom Worawit, Nakasatien Soontaree and Himathongkam Thep

\begin{abstract}
Background: Advance in medicine has led to an increase in life expectancy of elderly diabetic patients especially on the growing population called the "oldest old", those in their mid-80s upwards. The aim of this study is to describe clinical characteristics and outcomes of "oldest old" patients in a specialized diabetes center.

Methods: A retrospective review was conducted on medical records of type 2 diabetes who were older than 85 years at Theptarin hospital from September 2014 to August 2015.

Results: During the study period, there were 143 oldest old diabetic patients who visited our hospital regularly. Of the 133 active follow-up patients (median time of follow-up 15 years, range 1-30 years), $70.7 \%$ was female, the mean age of onset was $68.3 \pm 11.5$ years and duration of diabetes was $20.1 \pm 11.1$ years. According to the Charlson co-morbidity index (CCl), $35.3 \%$ of patients were classified as having severe co-morbidities. The mean A1C, blood pressure, LDL were $6.7 \pm 1.1 \%, 132 / 65 \mathrm{mmHg}$ and $80 \pm 29 \mathrm{mg} / \mathrm{dl}$ respectively. $66.9 \%$ of patients had tight glycemic control (A1C $<7 \%$ ) while $12.0 \%$ had poor control (A1C >8\%). Oral hypoglycemic agent (OHA) dual therapy was the most common treatment (26.3\%) followed by OHA monotherapy (22.6\%), insulin alone (19.5\%), diet therapy alone (12.7\%), and insulin plus OHA (8.3\%). Hypoglycemia was found in $10.5 \%$ of patients in previous 12 months. Diabetic retinopathy, chronic kidney disease, cardiovascular disease, and stroke were presented in 23.4, 54.9, 15.8, $18.0 \%$ of patients, respectively. Among patients whose received diabetic medications and resulted in very low level of A1C (A1C less than $6.0 \%$ ), only $20.0 \%$ underwent deintensification.
\end{abstract}

Conclusions: Our results revealed that real-world clinical outcomes of extreme elderly diabetic patients were diverse and being too "aggressive" diabetes treatment with older patients did occur frequently. Decision making in older people with diabetes is complex as chronic co-morbidities are very common.

Keywords: Oldest old, Type 2 diabetes, Thailand, Deintensification

\footnotetext{
* Correspondence: kamijoa@hotmail.com

Diabetes and Thyroid Center, Theptarin Hospital, Bangkok, Thailand
} 


\section{Background}

Over decades, Thailand has developed to become the second largest economy in term of gross domestic product (GDP) in Southeast Asia, and $10^{\text {th }}$ in Asia [1]. At the same time, Thailand has become an aging nation. According to the United Nations projection [2], the proportion of people aged over 65 years in Thailand will increase from $10.5 \%$ in 2015 to $26.6 \%$ (17.6 million people) in 2030, and $32.1 \%$ (20.5 million people) in 2040. In the mid-1980s, the term 'oldest old' referring to people aged 85 or older was introduced by gerontologists in an effort to focus attention on this growing segment of the population [3]. As the population continues to age since the term 'oldest old' was originally coined, it is important to note that the cut-off at age of 85 is fairly arbitrary and largely serves to create consensus and uniformity between studies. With the combination of aging population and diabetes epidemic, the number of elderly with type 2 diabetes (T2DM) will continue to rise.

Generally, the goal of diabetic treatment in the elderly is to maintain functional abilities and quality of life as well as to prevent diabetic complications. However, elderly patients have to cope not only with problems related to the management and treatment of diabetes, but also additional burden related to aging and associated comorbidities [4]. Older adults with diabetes are at greater risk of other common geriatric syndromes such as depression, cognitive impairment, urinary incontinence, falls, polypharmacy, etc. [5-7]. These factors are responsible for deviation from guideline of therapy. Most clinical evidence on the management of diabetes was derived from randomized controlled trials but the evidence from these trials is often not applicable to older people as they are usually excluded [8]. The risk of hypoglycemia from treatments presents the greatest significant barrier to optimal glycemic control for the very old patients [9]. Furthermore, the physiology of aging changes their responses to therapy and other problems such as dementia, depression and frailty have a significant impact on the treatment and management of their diabetes [5].

The complexities of diabetes care associated with aging will continue to dominate clinical practice in the foreseeable future. Moreover, Decision making in older people with diabetes is complex and factors other than biomedical goals need to be addressed including comorbidity and life expectancy. However, data for the oldest old group especially in diabetic patients are very limited. Therefore, the aim of this study is to describe the clinical characteristics and outcomes of oldest old with diabetes in a specialized diabetes center.

\section{Methods}

We retrospectively reviewed medical records of all T2DM with age more than 85 years who were treated between September 2014 and August 2015 at Theptarin hospital, Bangkok, Thailand. Patients who were regularly follow-up at least 2 times during the study period (duration of 12 months) were included. Exclusion criteria included patients who were lost to follow-up in the previous 12 months. Demographic data, recorded glycated hemoglobin (A1C) in the previous 12 months, lipid profiles, serum creatinine, previous history of acute diabetic complications including hypoglycemia in the previous 12 months, chronic diabetic complications, and other co-morbidities during the study period were retrieved. In the absence of these data in the charts, telephone contact was attempted by diabetic nurse educators. Those who were diagnosed with diabetes when they were $\geq 65$ years of age are referred to as elderlyonset diabetes and those diagnosed with diabetes at age $<65$ years are referred to as long-standing diabetes group.

Retinopathy was detected with the regular dilated eye examinations by ophthalmologists annually. Nephropathy was defined as persistent proteinuria greater than $500 \mathrm{mg} / 24 \mathrm{~h}$ or microalbuminuria greater than $30 \mathrm{mg} /$ $24 \mathrm{~h}$ confirmed on at least 2 occasions, 3-6 months apart. Hypertension was defined as blood pressure $>140 /$ $90 \mathrm{mmHg}$ and hypercholesterolemia was defined as low density lipoprotein (LDL) cholesterol $>100 \mathrm{mg} / \mathrm{dL}$. For A1C level, we defined very low as less than $6.0 \%$, moderately low as 6.0 to $6.4 \%$, not low as $6.5 \%$ or greater, and high as greater than $8.0 \%$. Safe margin of $\mathrm{A} 1 \mathrm{C}$ was defined as all values that are neither low nor high (6.5-8.0 \%) [10, 11]. Mild hypoglycemia was defined as hypoglycemia documented in the medical records which did not require additional support. Severe hypoglycemia was defined as hypoglycemia that required assistance to recover (e.g. ambulance callout, hospitalization, supporter/relative assistance to aid recovery).

The complexity of co-morbidities was determined by the Charlson comorbidity index (CCI) which originally was developed to predict the one-year mortality based on comorbidity data [12]. This index score composed of 19 medical conditions and patients were divided into three groups: mild, with CCI scores of 1-2; moderate, with CCI scores of $3-4$; and severe, with CCI scores $\geq 5$. Diabetic medication deintensification was defined as discontinuation or dosage reduction of any diabetic medication during the last 6 months of study period after A1C level went below $6.5 \%$.

\section{Setting and study population}

Theptarin Hospital is a private hospital in the central area of Bangkok and is one of the largest diabetes centers in Bangkok with over 2000 registered diabetic patients. Most diabetic patients are treated at diabetes 
clinic which has 12 diabetologists and a diabetes care team that includes diabetes nurse educators, dietitians and foot care specialists. Minority of elderly diabetic patients have regular follow-up by their primary physicians or a geriatrician. This retrospective study is approved by the Ethics board committee of Theptarin Hospital (No.02/2015).

\section{Statistical analysis}

Continuous variables were presented as mean (SD) and categorical variables were presented as proportions. Comparisons between new-onset diabetes in elderly group and long-standing diabetes group were done using an unpaired Student's t-test in continuous data and using a Chi-square test in categorical data. P-value $\leq 0.05$ was considered statistically significant. All statistical analyses were conducted using the Statistical Package for the Social Sciences (version 17.0; SPSS, Chicago, IL, USA).

\section{Results}

There are 143 oldest old diabetic patients visited our hospital regularly during the study period. The total number of these patients comprised of $5.0 \%$ of the total 2859 registered patients in our hospital at the same period. Ten patients died from various medical illnesses during studied. Of the remaining 133 active patients (median time of follow-up 15 years, range 1-30 years), $70.7 \%$ was female, the mean age of onset was $68.3 \pm$ 11.5 years and duration of diabetes was $20.1 \pm 11.1$ years. Of these, 84 patients $(63.2 \%)$ were diagnosed with diabetes at age $\geq 65$ years and formed the elderly-onset group (mean duration of diabetes $14.7 \pm 8.3$ years). The other 49 patients were diagnosed with diabetes at age $<$ 65 years and formed the long-standing diabetes group (mean duration of diabetes $29.3 \pm 9.1$ years). Diabetic retinopathy, nephropathy, cardiovascular disease, and stroke were presented in 23.4, 54.9, 15.8, $18.0 \%$, respectively. Multi-morbidity was highly prevalent in these patients. On average, patients experience 4 concurrent chronic medical conditions. According to the Charlson co-morbidity index (CCI), $42.9 \%$ of patients were classified as having moderate co-morbidities and $35.3 \%$ of patients were classified as having severe co-morbidities. Cerebrovascular diseases were also prominent (18.0\%). Diagnosed dementia was found in $22.6 \%$ of patients which almost half of them were bed-ridden. The demographic and general characteristics of the two patient groups of patients are summarized in Table 1. Metabolic controls and incidence of diabetic complications of both groups of oldest old diabetic patients were also showed in Table 1 and Fig. 1. Only the percentage of patients with diabetic retinopathy was statistically significantly higher in the long-standing diabetes group compared with the new-onset diabetes in elderly group $(P=0.014)$.
During the study period, 125 patients (89\%) had A1C levels measured on average of 3 times (range 1-5 times) per year. The mean of $\mathrm{A} 1 \mathrm{C}$ during the past 12 months was $6.7 \pm 1.1 \% .66 .9$ percents of patients had tight glycemic control (A1C $<7 \%$ ) while only $12.0 \%$ of patients had poorly controlled diabetes (HbA1c $>8 \%$ ). Very low level of A1C (less than $6.0 \%$ ), moderately low level of A1C (6.0 to $6.4 \%)$, safe margin of A1C (6.5 to $8.0 \%$ ) were found in $23.3,22.6,39.8 \%$, respectively. The last measurement of mean blood pressure and LDL were $132 / 65 \mathrm{mmHg}$ and $80 \pm 29 \mathrm{mg} / \mathrm{dl}$, respectively. Eightytwo percent of patients were on anti-hypertensive drugs and $76.7 \%$ of patients were taking statins at the time of study. Regarding diabetic treatments, oral hypoglycemic agent (OHA) dual therapy was the most common treatment $(26.3 \%)$ followed by OHA monotherapy (22.6 \%), insulin alone (19.5\%), diet therapy alone (12.7\%), and insulin plus OHA (8.3\%). For OHA-treated patients, metformin was the most commonly prescribed diabetic medication (38.3\%), followed by sulphonylurea (24.0\%), and DPP4 inhibitor (DPP4i) (24.0\%). Hypoglycemia was found in $10.5 \%$ of patients in previous 12 months.

Among patients whose received diabetic medications and resulted in very low level of A1C (A1C less than $6.0 \%$ ), only $20.0 \%$ underwent deintensification. The details of diabetic medications deintensification according to range of glycemic control were showed in Fig. 2. In the past 12 months, there were 2 patients who experienced severe hypoglycemia and 12 patients had symptomatic hypoglycemia (total rate of symptomatic hypoglycemia $=10.5 \%$ ). The occurrence of hypoglycemia was highest in the insulin-treated patients as shown in Fig. 3.

\section{Discussions}

The world population is getting older in both developed and developing countries but this trend is occurring at a much faster rate in developing countries. A population is considered 'aging' when $10 \%$ of the total population is 60 or older, and $7 \%$ of the population is 65 or older. A society will turn into an 'aged society' and 'superaged society' once the proportion aged 65 or over is greater than 14 and $20 \%$ of the population, respectively [2]. Thailand now stands in the forefront of high middleincome countries will move from being an 'aging' to an 'aged' society in less than a decade from now, and to a super-aged status in about half a decade. Among ASEAN countries, Thailand ranks second after Singapore in term of highest proportion of elderly people. This demographic change will produce wide-ranging effects on the country's economy and social structure.

Frailty increases significantly with age. The 'oldest old' group (people aged 85 and older) therefore are usually contains the frailest members of society, who require 
Table 1 Demographic data, pattern of diabetes treatment, and diabetic complications in oldest old diabetic patients

\begin{tabular}{|c|c|c|c|c|}
\hline & $\begin{array}{l}\text { Total patients } \\
(N=133)\end{array}$ & $\begin{array}{l}\text { Long-standing } \\
\text { diabetes }(N=49)\end{array}$ & $\begin{array}{l}\text { Elderly-onset } \\
\text { diabetes }(N=84)\end{array}$ & p-value \\
\hline Age (yrs) & $87.7 \pm 3.0$ & $87.2 \pm 3.0$ & $88.1 \pm 2.9$ & 0.083 \\
\hline Female (\%) & 94 (70.7 \%) & $38(77.6 \%)$ & $56(66.7 \%)$ & 0.186 \\
\hline DM duration (yrs) & $20.1 \pm 11.1$ & $29.3 \pm 9.1$ & $14.7 \pm 8.3$ & $<0.001$ \\
\hline Age of onset (yrs) & $68.3 \pm 11.5$ & $57.8 \pm 9.3$ & $74.3 \pm 7.7$ & $<0.001$ \\
\hline Follow-up time (yrs) & $15.1 \pm 7.8$ & $18.3 \pm 8.3$ & $13.2 \pm 6.8$ & $<0.001$ \\
\hline $\mathrm{BMI}\left(\mathrm{kg} / \mathrm{m}^{2}\right)$ & $23.4 \pm 4.2$ & $23.4 \pm 4.0$ & $23.5 \pm 4.4$ & 0.971 \\
\hline \multicolumn{5}{|l|}{ Smoking status: } \\
\hline -Never & $116(87.2 \%)$ & 45 (91.8\%) & 71 (84.5 \%) & \\
\hline -Ex-smokers & 15 (11.3\%) & 4 (8.2 \%) & $11(13.1 \%)$ & \\
\hline -Current & $2(1.5 \%)$ & $0(0 \%)$ & $2(2.4 \%)$ & \\
\hline \multicolumn{5}{|l|}{ Comorbidities } \\
\hline -Myocardial Infarction & $21(15.8 \%)$ & 10 (20.4 \%) & $12(14.2 \%)$ & \\
\hline -Stroke & 24 (18.0 \%) & $10(20.4 \%)$ & $14(16.7 \%)$ & \\
\hline -Peripheral arterial disease $\mathrm{e}^{\mathrm{a}}$ & $26(23.4 \%)$ & $9(22.0 \%)$ & $17(21.3 \%)$ & \\
\hline -Chronic kidney disease & 73 (54.9\%) & $25(51.0 \%)$ & $48(57.1 \%)$ & \\
\hline -Cancer & $8(6.0 \%)$ & 2 (4.1\%) & $6(7.1 \%)$ & \\
\hline -Dementia & $30(22.6 \%)$ & $12(24.5 \%)$ & 18 (21.4 \%) & \\
\hline \multicolumn{5}{|l|}{ Charlson comorbidity index } \\
\hline -Mild (1-2) & $29(21.8 \%)$ & $10(20.4 \%)$ & 19 (22.6 \%) & \\
\hline -Moderate (3-4) & 57 (42.9\%) & 21 (42.9\%) & 36 (42.9 \%) & \\
\hline -Severe $(\geq 5)$ & $47(35.3 \%)$ & 18 (36.7 \%) & 29 (34.5\%) & \\
\hline $\mathrm{HbA}_{1 \mathrm{c}}(\%)$ & $6.7 \pm 1.1$ & $6.8 \pm 1.0$ & $6.7 \pm 1.1$ & 0.454 \\
\hline Frequency of $\mathrm{HbA}_{1 c}$ testings (times per year) & $3.1 \pm 1.4$ & $3.2 \pm 1.4$ & $3.1 \pm 1.4$ & 0.714 \\
\hline Blood pressure (mmHg) & $132 \pm 16 / 65 \pm 11$ & $131 \pm 16 / 64 \pm 13$ & $133 \pm 15 / 67 \pm 9$ & 0.582 \\
\hline $\mathrm{LDL}(\mathrm{mg} / \mathrm{dL})$ & $80 \pm 29$ & $81 \pm 34$ & $79 \pm 26$ & 0.779 \\
\hline Diabetic retinopathy (\%) $^{\mathrm{b}}$ & $22(23.4 \%)$ & $14(37.8 \%)$ & $8(14.0 \%)$ & 0.014 \\
\hline \multicolumn{5}{|l|}{ Pattern of diabetes treatment } \\
\hline -Diet control alone & 17 (12.8\%) & $4(8.2 \%)$ & $13(15.5 \%)$ & 0.028 \\
\hline -Oral hypoglycemic agents & 79 (59.4 \%) & $23(46.9 \%)$ & $56(66.5 \%)$ & 0.031 \\
\hline -Insulin therapy & $37(27.8 \%)$ & $22(44.9 \%)$ & $15(18.0 \%)$ & 0.013 \\
\hline
\end{tabular}

${ }^{\mathrm{a}}$ Data were available in 111 patients

${ }^{\mathrm{b}}$ Data were available in 94 patients

support from health and social services to maintain good quality of life [13]. However, each individual varies widely in terms of demography, social and health characteristics [14]. Aging is unequal and is not a matter of chronological age alone. Also, there is a pronounced sex imbalance with women greatly outnumber men especially among the oldest old. With advancing age, older patients suffer more from various medical conditions including diabetes. Unfortunately, there is little evidence to guide recommendations for diabetes management in old age when issues of multi-morbidity, polypharmacy, frailty and dementia coexist [10]. While older people tend to have normal hepatic glucose output, aging is associated with declining pancreatic islet cell function and lower insulin levels [5]. Elderly patients with diabetes mellitus can be divided into two subgroups: elderly age-at-onset (or senile diabetes) and younger age-at-onset (or long lasting diabetes) groups. Those who develop type 2 diabetes in old age are more likely to have near normal fasting glucose levels but significant postprandial hyperglycemia $[15,16]$. In contrast to the new-onset diabetes in elderly, elderly with longstanding diabetes tend to develop more diabetic complications and require particular attention. As a result, the differences of demographic and clinical characteristics of 


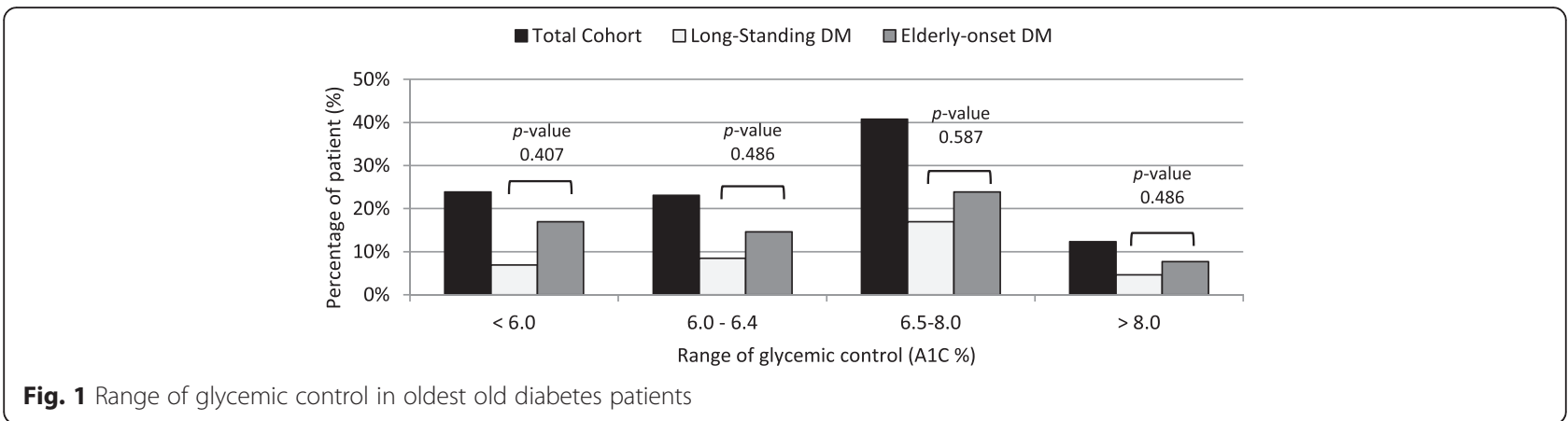

these two groups lead to complexity in generalization of treatment or adherence to guideline. Moreover, most recommendations and guidelines tend to focus on a single disease rather than taking into account of managing chronic illness of aging populations. A recent global survey among leading worldwide diabetologists, the results from an example case of the oldest old revealed that "risk of hypoglycemia from treatment", "life expectancy", and "important comorbidities" were ranked among the top three parameters when set personalized target A1C [17]. The median target $\mathrm{A} 1 \mathrm{C}$ had been proposed at $8.0 \%$ (range 6.5-9.0 \%) for the oldest old example case.

In the present study, there were heterogeneities of health status of oldest old diabetic patients and varieties of diabetes care patterns among diabetologists. About $13 \%$ of oldest old diabetic patients especially in senile diabetes group can possibly be effectively managed with diet only. Even though almost $80 \%$ of elderly-onset diabetic patients in our cohort had moderate to severe comorbidity conditions, their glycemic control were relatively better when compared with long-standing diabetic patients. The possible reasons might be explained by the benign nature of new-onset diabetes in elderly [5] and also various comorbidity conditions especially chronic kidney diseases in these patients might make patients more aware of eating habits.
Approximately one fourth of patients especially in long lasting diabetes group were on insulin treatment (mostly insulin analog). Although many insulin-based regimens have been used safely in elderly patients, hypoglycemia is a concern and presents a challenge for obtaining optimal glycemic control [18]. The main reasons for our diabetologists to use insulin in extreme elderly are comorbid conditions of patients which precluded from use of oral medications and failure of oral medications in bringing glycemic control to target. In our study, we found that symptomatic hypoglycemia tend to occur with insulin-treated patients. Mixed split insulin regimen was associated with the highest incidence of hypoglycemia. This finding might come from variable eating patterns of some elderly patients. In those patients, a basal-plus or basal-bolus regimen might be better options in patients who failed basal insulin regimen. As age, frailty, insulin treatment, and chronic kidney disease are known risk factors for hypoglycemia and hypoglycemic symptoms may be mistaken for other conditions associated more commonly with advanced ages, strategies to prevent hypoglycemia in very old patients should be emphasized. Focus should be on educating caregivers to recognize the signs and symptoms of hypoglycemia and to frequently perform home blood glucose monitoring.

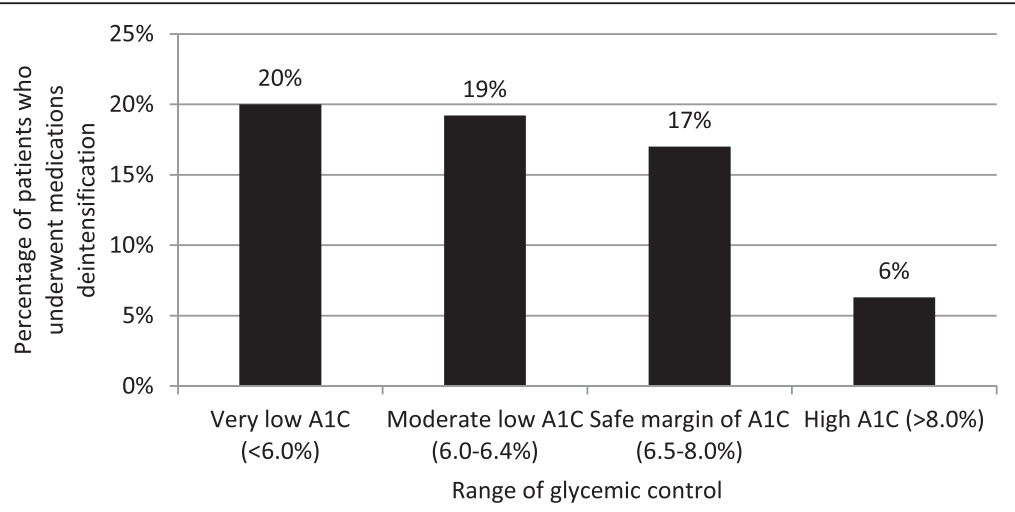

Fig. 2 Rate of Medications Deintensification according to range of glycemic control 


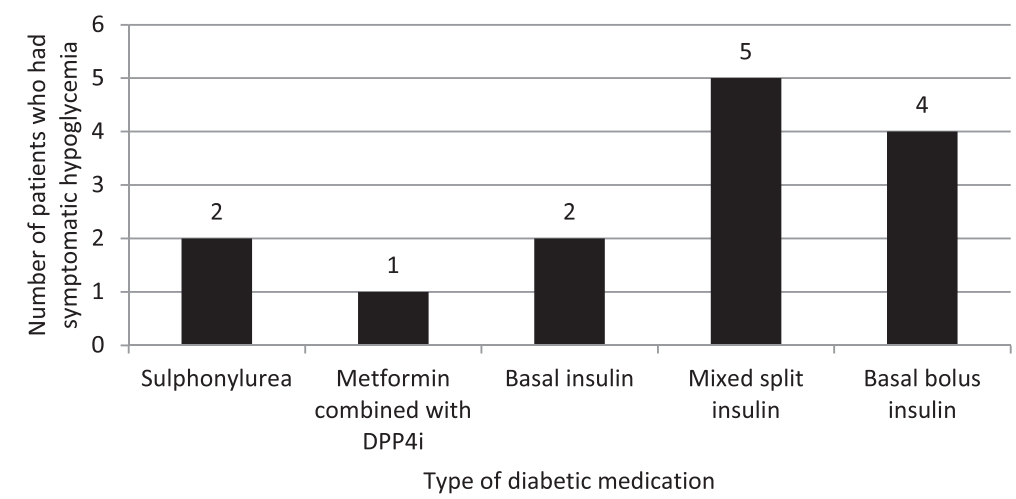

Fig. 3 Incidence of symptomatic hypoglycemia in oldest old diabetes patients according to type of treatments

For OHA-treated patients, metformin was commonly prescribed diabetic medication. This finding is contrast with a recent study from China which showed sulphonylurea was the most commonly used oral drug for elderly Chinese patients [19]. Although some concerns about an increase in the risk of metformin-associated lactic acidosis in very old patients and lack of data in this extreme aging population, the risk of lactic acidosis is very rare and preventable $[20,21]$. In view of favorable profiles of metformin, it would continue to be used as a first line treatment in oldest old diabetes patients with adjusted dosage to renal function. In patients who are using sulfonylurea drugs, the presence and frequency of hypoglycemia should be evaluated at each visit. In our study, we also found that DPP-4 inhibitors were prescribed as the second most common drugs for the oldest old patients. A recent retrospective study on DDP-4 inhibitors prescribed to elderly diabetes patients (median age 70 years, range 60-92 years) found that median $\mathrm{A} 1 \mathrm{C}$ improved from 8.3 to $7.4 \%$ and DDP-4. inhibitors treated patients had a lower rate of documented hypoglycemia than the non-DPP-4 inhibitors treated group (3 vs. $8 \%$ ) [22]. Therefore, DPP-4 inhibitors would be an attractive choice for oldest old patients for its lower rate of hypoglycemia and neutral weight effects. Another class of adjuvant OHA which was popularly used in East Asian countries but not in our patients is alphaglucosidase inhibitors ( $\alpha-\mathrm{GI})$. Even though $\alpha-\mathrm{GI}$ is an another attractive choice in elderly patients for low risk of hypoglycemia, gastrointestinal side effects and its clinical response which depends on preserved $\beta$-cell function limit its widespread use [23]. However, a recent populationbased nationwide cohort study from Taiwan showed that $\alpha$-GI (Acarbose) use reduced the risk of colorectal cancer in a dose-dependent manner [24]. The potential mechanism of this finding might be explained by the effects of Acarbose in reducing colonic transit time and changes in the fecal concentration of bile acids [25]. This interesting finding would deserve more study in a prospective study in elderly patients.

Older adults with diabetes are also at high risk for polypharmacy, functional disabilities, and common geriatric syndromes that include cognitive impairment, depression, urinary incontinence, falls, and persistent pain. Diabetes and its comorbidities are associated with Alzheimer's disease, vascular dementia, and mixed dementia which the prevalence of dementia ranges from $18-38 \%$ among those aged 85 and older, and from 28$44 \%$ among those aged 90 and older [26, 27]. The increasing prevalence of mixed pathologies of dementia and susceptibility to side effects of treated medications among the oldest old make a difficulty in treatment of dementia in this age group. In our cohort, we found that more than one fifth of patients suffered from dementia and half of these patients had severe dementia with almost bed-ridden status. In theory, targets in frail older people with diabetes should focus on short-term day to day blood glucose levels to avoid hypoglycemia, rather than basing diabetes care around a long term A1C strategy. However, in a real-world setting, a large proportion of these patients are still receiving aggressive diabetic medications from specialists. This finding is similar to a recent study in US Veterans Health Administration which reported that only $27 \%$ of patients who already had very low $\mathrm{A} 1 \mathrm{C}$ or blood pressure underwent medication deintensification [28]. Therefore, overtreatment of diabetes in extreme age patients who had low life expectancy still prevails as showed in our study. Encouraging treating physicians to consider deintensification when appropriate should be focused as one of clinical performance index in diabetes care.

For chronic diabetic complications, our data also clearly showed that diabetic retinopathy (DR) was much more common in long-standing diabetes than elderly-onset diabetes (38 VS. 14\%). A recent study of DR prevalence in elderly Chinese population (mainly elderly-onset diabetes) 
revealed similar prevalence at around $16 \%$ [29]. Therefore, even though the prevalence of DR is relatively low in elderly patients but long-standing diabetes patients suffer much higher rate due to long duration of diabetes. Timely screening and early treatment are still the basis of preventing blindness from diabetic retinopathy. Another medical condition which revealed a very high rate in oldest old patients was chronic kidney disease (CKD). The clinical and pathologic heterogeneity of nephropathy in type 2 diabetes especially in elderly patients reflect various causes of chronic kidney disease in this age group apart from metabolic consequence of diabetes. Optimal care for these patients is complex and best managed using comprehensive multi-factorial risk-reduction strategies with multidisciplinary team-based care [30-31]. Diabetes care should be individualized based on frailty, life expectancy, and comorbid conditions.

The strengths of this study are that patients were followed up by the same diabetologists for a long period of time enabling us to collect details data and that this cohort study is the first comprehensive report on oldest old diabetes patients in Thailand. However, limitations do exist. First, the retrospective nature of the study resulted in relatively incomplete and missing data on some aspects such as neuropathy evaluation. Second, we used medical records to represent drug prescriptions rather than the actual dispensing data and also there was no data on patient adherence to treatment. Third, our study came from a single hospital in a private setting located in the central of Bangkok which limits the generalizability of the findings.

\section{Conclusions}

In conclusion, managing the increasing population of extreme elderly people with diabetes represents a significant challenge. Our study revealed that real-world clinical outcomes of these diabetic patients were diverse and being too "aggressive" on diabetes treatment in older patients occurred frequently. Decision making in older people with diabetes is complex as chronic co-morbidities are very common in this group of patients. It is a challenge for policy makers in dealing with growing oldest old with diabetes population. Results from this retrospective study suggest opportunities to look into reducing overtreatment and rethinking about quality versus quality of life. This study also brings out the importance of recognizing heterogeneity of the population when it comes to treatment decision.

\section{Abbreviations}

a-Gl: alpha-glucosidase inhibitors; CCl: Charlson comorbidity index; CKD: chronic kidney disease; DR: diabetic retinopathy; DPP4i: DPP4 inhibitor; A1C: glycated hemoglobin; LDL: low density lipoprotein; OHA: oral hypoglycemic agent; T2DM: type 2 diabetes.

\section{Acknowledgments}

The authors wish to thank Mr. Phawinpon Chotwanvirat for his excellent graphical assistance, Mrs. Tanya Vannapruegs for her professional English editing, Professor Dr. Rajata Rajatanavin, Faculty of Medicine, Mahidol University for his generous advice, inspiring guidance and encouragement, and finally the staffs of Theptarin Hospital for all their support and help.

Funding

No source of funding was applied in this retrospective study.

Availability of data and materials

The dataset supporting the conclusions of this article is available on request.

\section{Authors' contributions}

TY performed the statistical analyses, interpreted the data and drafted the manuscript. NS, KS contributed to the statistical analyses, interpretation of the data and revised the manuscript critically before submission. WE, VS, AT, KW and HT made substantial contributions to the discussion of results. They revised the manuscript critically before submission. All authors read and approved the final manuscript.

\section{Competing interests}

The authors declare that they have no competing interests.

Consent for publication

Not applicable.

\section{Ethical approval and consent to participant}

This retrospective study is approved by the Ethics board committee of Theptarin Hospital (No.02/2015). No inform consent to participant was required as a retrospective study.

Received: 17 March 2016 Accepted: 26 May 2016

Published online: 01 June 2016

\section{References}

1. World Bank - Thailand's economy facts, statistics, project information, and development. http://www.worldbank.org/en/country/thailand (accessed 16 Jan, 2016)

2. World Population Ageing 1950-2050, United Nations. http://www.un.org/ esa/population/publications/worldageing19502050/pdf/195thail.pdf (accessed 16 Jan, 2016).

3. Cornoni-Huntley JC, Foley DJ, White LR, Suzman R, Berkman LF, Evans DA, et al. Epidemiology of disability in the oldest old: methodological issues and preliminary findings. Milbank Mem Fund Q Health Soc. 1985;63:350-76.

4. Abdelhafiz AH, Sinclair AJ. Management of type 2 diabetes in older people. Diabetes Ther. 2013:4:13-26.

5. Kirkman MS, Briscoe VJ, Clark N, Florez H, Haas LB, Halter JB, et al. Diabetes in older adults. Diabetes Care. 2012;35:2650-64.

6. Lu FP, Lin KP, Kuo HK. Diabetes and the risk of multi-system aging phenotypes: a systematic review and meta-analysis. PLoS One. 2009;4:e4144.

7. Huang ES, Laiteerapong N, Liu JY, John PM, Moffet HH, Karter AJ. Rates of complications and mortality in older patients with diabetes mellitus: the diabetes and aging study. JAMA Intern Med. 2014;174:251-8.

8. Mutasingwa DR, Ge H, Upshur REG. How applicable are clinical practice guidelines to elderly patients with comorbidities? Can Fam Physician. 2011;57:e253-62.

9. Seaquist ER, Anderson J, Childs B, Cryer P, Dagogo-Jack S, Fish L, et al. Hypoglycemia and diabetes: a report of a workgroup of the American Diabetes Association and the Endocrine Society. Diabetes Care. 2013;36:1384-95.

10. Sinclair A, Morley JE, Rodriguez-Manas L, Paolisso G, Bayer T, Zeyfang A, et al. Diabetes mellitus in older people: position statement on behalf of the International Association of Gerontology and Geriatrics (IAGG), the European Diabetes Working Party for Older People (EDWPOP), and the International Task Force of Experts in Diabetes. J Am Med Dir Assoc. 2012;13:497-502.

11. Lee SJ, Eng C. Goals of glycemic control in frail older patients with diabetes. JAMA. 2011;305:1350-1.

12. Charlson ME, Pompei $P$, Ales KL, MacKenzie CR. A new method of classifying prognostic comorbidity in longitudinal studies: development and validation. J Chronic Dis. 1987;40:373-83. 
13. Robine JM, Michel JP, Herrmann FR. Who will care for the oldest people in our aging society? BMJ. 2007;334:570-1.

14. Garfein AJ, Herzog AR. Robust aging among the young-old, old-old, and oldest-old. J Gerontol B Psychol Sci Soc Sci. 1995:50:577-87.

15. Meneilly GS. Pathophysiology of type 2 diabetes in the elderly. Clin Geriatr Med. 1999;15:239-53.

16. Motta M, Bennati E, Capri M, Ferlito L, Malaguarnera M. Diabetes mellitus in the extreme longevity. Exp Gerontol. 2008;43:102-5.

17. Cahn A, Raz I, Kleinman Y, Balicer R, Hoshen M, Lieberman N, et al. Clinical assessment of individualized glycemic goals in patients with type 2 diabetes: formulation of an algorithm based on a survey among leading worldwide diabetologists. Diabetes Care. 2015;38:2293-300.

18. Weber P, Meluzínova H, Kubesova H, Polcarova V, Kocourhova B, Striova A et al. Insulin treatment in diabetics $75+$ years: experiences and results in outpatient care. Adv Gerontol. 2008;21:143-7.

19. Zhang L, Ji L, Guo L, Lu J, Tian H, Zhu D, et al. Treatment patterns and glycemic control in older adults with type 2 diabetes mellitus receiving only oral antidiabetes drugs in China. Diabetes Technol Ther. 2015;17:816-24.

20. Chan NN, Brain HP, Feher MD. Metformin-associated lactic acidosis: a rare or very rare clinical entity? Diabet Med. 1999;16:273-81.

21. Mathieu C. Metformin-associated lactic acidosis: time to let it go? J Diabetes Complications. 2015:29:974-5.

22. Viljoen A, Meek C, Gadsby R, Viljoen S, Langerman H, Sinclair A. The tolerability and safety of DPP-4 inhibitors for the treatment of older people with type 2 diabetes mellitus: an observational study. Br J Diabetes Vasc Med. 2013:13:187-91.

23. van de Laar FA, Lucassen PL, Akkermans RP, van de Lisdonk EH, Rutten GE, van Weel C. Alpha-glucosidase inhibitors for patients with type 2 diabetes: results from a Cochrane systematic review and meta-analysis. Diabetes Care. 2005:28:154-63.

24. Tseng YH, Tsan YT, Chan WC, Sheu WH, Chen PC. Use of an a-glucosidase inhibitor and the risk of colorectal cancer in patients with diabetes: A nationwide, population-based cohort study. Diabetes Care. 2015;38:2068-74.

25. Weaver GA, Tangel $C T$, Krause JA, et al. Biomarkers of human colonic cell growth are influenced differently by a history of colonic neoplasia and the consumption of acarbose. J Nutr. 2000;130:2718-25.

26. Gardner R, Valcour V, Yaffe K. Dementia in the oldest old: a multi-factorial and growing public health issue. Alzheimers Res Ther. 2013;5:27.

27. World Health Organization. Dementia: a public health priority. In: Book Dementia: A Public Health Priority. Geneva: WHO; 2012. p. 12-9.

28. Sussman JB, Kerr EA, Saini SD, Holleman RG, Klamerus ML, Min LC, et al. Rates of deintensification of blood pressure and glycemic medication treatment based on levels of control and life expectancy in older patients with diabetes mellitus. JAMA Intern Med. 2015;175:1942-9.

29. Xin L, Zhaoyan W. Prevalence and incidence of retinopathy in elderly diabetic patients receiving early diagnosis and treatment. Exp Ther Med. 2013;5:1393-6

30. Katherine T, George B, Rudolf B, Jane C, lan B, Jordi GF, Irl H, et al. Diabetic kidney disease: a report from an ADA Consensus Conference. Diabetes Care. 2014:37:2864-83.

31. von Faber M, Bootsma-van der Wiel A, van Exel E, Gussekloo J, Lagaay AM, van Dongen $\mathrm{E}$, et al. Successful aging in the oldest old: who can be characterized as successfully aged? Arch Intern Med. 2001;161:2694-70.

\section{Submit your next manuscript to BioMed Central and we will help you at every step:}

- We accept pre-submission inquiries

- Our selector tool helps you to find the most relevant journal

- We provide round the clock customer support

- Convenient online submission

- Thorough peer review

- Inclusion in PubMed and all major indexing services

- Maximum visibility for your research

Submit your manuscript at www.biomedcentral.com/submit
C Biomed Central 